\title{
Análise estratégica sobre o emprego de federação de identidade no canal de Internet das organizações
}

\author{
Heitor Luiz Murat de Meirelles Quintella \\ Universidade Estadual do Rio de Janeiro \\ José Marcelo de Freitas Vilela \\ Universidade Federal Fluminense
}

\begin{abstract}
Resumo
A Federação de Identidade, como um padrão de segurança e de intermediação de informações privadas de identidade, desponta como uma solução real no mercado e tem tomado corpo através de três alianças ou grupos: Shibboleth, WS-Federation e Liberty Alliance. Este trabalho realiza uma análise estratégica desta nova tecnologia a partir da coleta de várias percepções e expectativas de companhias e usuários-chaves brasileiros.

As atividades de federação de identidade foram percebidas com capacidade de obtenção de vantagens competitivas pela influência positiva na estrutura da indústria e em algumas metas estratégicas. Estudos prospectivos em fase de pré-lançamento de produtos e serviços servem para antecipar problemas que normalmente seriam solucionados em versões de correção depois do produto/serviço já lançado no mercado, o que poderia ter custos muito elevados. Neste caso específico, este trabalho identifica importantes deficiências, como incapacidade de se trazer uma vantagem "sustentável" e de criar barreiras a novos entrantes.
\end{abstract}

Palavras-chave

Federação de identidade, competitividade, qualidade nos serviços.

\section{Identity federation on organizational Internet channel strategic analysis}

\begin{abstract}
Identity Federation, as a standard of security and identity data privacy intermediation, seems to be a real market solution and has been proposed by three alliances or groups: Shibboleth, WS-Federation and Liberty Alliance. This work makes a strategic analysis of this new technology by gathering several perceptions and expectations of Key Brazilian companies and users.

The identity federation activities were perceived as providing high potential of granting competitive advantage by the positive influence in the industry structure and in some strategic Objectives. Prospective Studies carried out in the pre-launch stages of products and services are extremely useful to anticipate problems that are normally solved after costly measures taken when the product/service has already been launched in the market. In this particular case, this work identifies important deficiencies which were proven worthy of consideration by future implementers in the business arena as no sustainable advantages and no barriers to entry.
\end{abstract}

Key words

Identity federation, competitiveness, quality of services. 


\section{INTRODUĈ̣̃O}

A Internet desenvolveu-se inicialmente, com uma forte interação entre provedores de informação e usuários em anonimato. Considerando a continuidade desta evolução, principalmente com o comércio eletrônico, um dos grandes desafios enfrentados neste meio é a necessidade de se ter uma "prova de identidade" através de uma corrente eletrônica de confiança (AberdeenGroup, 2002). Desta forma, diferentes participantes, como consumidores, provedores, compradores e vendedores, poderão interagir comercialmente e atender obrigações contratuais com conhecimento e confiança entre si sem que parte de sua privacidade perca o anonimato.

Este artigo tem por objetivo trazer subsídios estratégicos e de apoio à decisão para que empresas que possuam atuação no canal da Internet possam potencializar seus serviços, além de definirem um melhor emprego das atividades de federação de identidade no seu negócio. Com isto, realiza-se uma análise sobre as atividades de federação de identidade sob a ótica da competitividade para empresas participantes e sob a ótica da satisfação do usuário que utilizará tais facilidades, verificando-se os seguintes aspectos:

a) Comparar as percepções e expectativas entre os usuários pesquisados e empresas interessadas na implementação das atividades de federação de identidade.

b) Verificar se a prática de federação de identidade traz vantagem competitiva para as empresas participantes.

\section{ATIVIDADES DE FEDERACÃO DE IDENTIDADE}

As atividades de federação de identidade visam permitir que se integrem as várias identificações/logins de uma pessoa em uma única identificação na Internet. Esta solução tem tomado corpo no mercado através de três principais iniciativas: Shibboleth, WS-Federation e Liberty Alliance Project. Estas iniciativas promovem especificações, alternativas e empregabilidade das atividades de federação de identidade, e são compostas por grupos (membros) dos mais diversos segmentos organizacionais: instituições de ensino, indústrias, fornecedores de solução tecnológica, consumidores, revendedores etc.

Com a crise que se instalou na Nova Economia no ano de 2001, provocando uma forte reavaliação dos negócios na Internet, sugere-se que novas tendências tecnológicas venham a ter forte foco em minimização de custos, assim como, para sua consolidação, são expostas por maiores exigências quanto aos retornos de investimento ou justificativas mais fundamentadas para se tornarem realmente uma onda convergente de tecnologia.

Para o estudo de expectativa e percepção de qualidade sob a ótica do usuário e capacidade de trazer vantagens competitivas para as empresas participantes, identificou-se um conjunto de atividades referentes à federação de identidade que fazem parte do objetivo, da missão ou especificação de todas as iniciativas apontadas.

As atividades identificadas são:

- Login Único (Single Sign-on): O usuário se autentica (digita o login e a senha) uma vez e consegue, a partir daí, acessar sites de diferentes empresas que prestam serviços na Internet, desde que pertençam a um mesmo Círculo de Confiança.

- Arranjo das organizações formando um Círculo de Confiança: Para unificar as várias identificações na Internet a uma pessoa só, é necessário que as empresas envolvidas criem laços de confiança, pois o usuário precisa ter não somente confiança nas empresas envolvidas, como ter certeza de quais empresas estão envolvidas e se elas possuem comprometimento suficiente para gerenciar, trafegar e controlar a sua identificação.

- Intermediação e controle dos dados dos usuários: Esta é a atividade de "federar" a identidade do usuário, onde a identificação e alguns dos seus dados em uma empresa (site) são associados à identificação deste mesmo usuário em outra empresa (site). Esta atividade só é acionada após o consentimento prévio do usuário.

O Liberty Alliance Project (Liberty Alliance Project, 2003b) sugere uma arquitetura para implementação das atividades de federação de identidade com base em componentes utilizando tecnologias como:

- HTTP redirection (código de resposta 302, conforme protocolo $H T T P$ );

- HTTP POST acionados por botões de submissão em formulários $w e b$;

- rotinas em linguagem JavaScript;

- protocolo SOAP (simple object access protocol) Binding (Liberty Alliance Project, 2003c) com base em mensagens $S O A P$ versão 1.1 e com adaptações na especificação de SAML (OASIS, 2003);

- mensagens de protocolo no estilo RPC (remote procedure call) transportadas via $S O A P$ versão 1.1 .

A arquitetura sugerida na especificação WS-Federation Specification (IBM et al., 2003) faz uso das funcionalidades da tecnologia de Web Services, estendendo os fundamentos especificados em WS-Policy (IBM et al., 2002b), WS-Security (IBM et al., 2002a) e WS-Trust (IBM et al., 2002c).

Para proteger a privacidade em ambiente de federação, WS-Federation destaca controles adicionais envolvendo atributos de serviço que permitem às partes envolvidas terem informações necessárias para se autorizar o compartilhamento de dados entre si e com outras partes envolvidas. Também, para facilitar o single sign-on em que múltiplas identidades precisam ser mapeadas automaticamente, man- 
tendo um grau desejável de privacidade, esta especificação propõe opcionalmente o uso de Serviços de Pseudônimo, permitindo que requisitantes possuam diferentes "apelidos" para acesso a diferentes serviços (recursos) ou sites.

Assim como proposto em especificação do Liberty (Liberty Alliance Project, 2003a), WS-Federation ressalta a necessidade de se ter diferentes informações em formato de "metadados": política de segurança ou Schema e WSDLs (Web Services Description Language) dos serviços disponibilizados no ambiente.

\section{CADEIA DE VALOR NA INTERNET}

Segundo Porter (2001), a Internet é uma tecnologia composta de um conjunto poderoso de ferramentas que podem ser usadas, adequadamente ou inadequadamente, por quase todas as indústrias e como parte de qualquer estratégia.

Neste contexto, consideram-se os seguintes questionamentos: Quem irá capturar os benefícios que a Internet cria? Qual será o impacto da Internet sobre a estrutura das indústrias? A Internet será capaz de aumentar ou reduzir as receitas? Qual será o impacto na estratégia das empresas? A Internet ajuda ou prejudica a capacidade de as companhias obterem vantagem sustentada sobre os seus competidores?

Porter destaca estes questionamentos chaves como resultado de uma fase exploratória deste ambiente e que, no momento, pode-se analisar a Internet de forma mais clara, em que muitas das experiências iniciais foram desastrosas por não considerarem os fatores e as verdades que a abordagem na estratégia tradicional pode revelar.

A arquitetura da Internet em conjunto com outras melhorias em arquitetura de software e ferramentas de desenvolvimento, tornou a Tecnologia da Informação (TI) a mais poderosa ferramenta para estratégia. É muito mais fácil customizar um pacote de aplicações de Internet para atender ao posicionamento estratégico único da companhia. Através de uma plataforma de TI comum por toda a cadeia de valor, a arquitetura e os padrões da Internet tornam possível construir sistemas integrados e customizados que reforçam o encaixe entre as atividades.

A ferramenta básica para entender a influência da TI nas companhias é a cadeia de valor. Quando uma companhia compete em qualquer segmento da indústria, ela executa atividades interconectadas de criação de valor, como a operação de força de vendas, fabricação de componentes ou distribuição de produtos. Adicionalmente, estas atividades possuem pontos de conexão com atividades de fornecedores, canais e consumidores. A cadeia de valor é um modelo para se identificar todas estas atividades e analisar como elas afetam tanto os custos da companhia quanto o valor entregue para os compradores.

Através da incorporação de conjuntos comuns e abertos de protocolos de comunicação, a tecnologia da Internet provê uma infra-estrutura padronizada - uma interface intuitiva (browser) para acesso à informação, e de fácil conectividade.

Para verificar como estes avanços tecnológicos afetam em última instância a cadeia de valor, Porter destaca a evolução da TI nos negócios como cinco estágios sobrepostos: 1. Os primeiros sistemas de TI automatizavam transações discretas como entrada de pedido e contabilidade.

2. Este estágio envolvia automação completa e melhorias funcionais nas atividades individuais, como gestão de recursos humanos, operações para força de venda e projeto de produto.

3. Este estágio, que está sendo acelerado pela Internet, envolve integração de atividades cruzadas, como atividades de venda relacionadas a processamento de pedidos. Neste estágio, aplicam-se sistemas como customer relationship management (CRM), supply chain management (SCM) e enterprise resource planning (ERP).

4. Este estágio, ainda se iniciando, permite a integração da cadeia de valor e de todo o sistema de valor. Ou seja, o conjunto de cadeias de valor em todo um segmento industrial cerca as cadeias das camadas de fornecedores, canais e consumidores. SCM e CRM estão começando a mesclar, com aplicações fim-a-fim, envolvendo consumidores, canais, e fornecedores, com, por exemplo, serviços de entrega, aquisição e manufatura.

5. Neste estágio, a TI será usada não somente para conectar as várias atividades e participantes no sistema de valor, mas para otimizar seus trabalhos em tempo real. Por exemplo, o projeto de produto será otimizado e customizado com base nas entradas (informações) provenientes não somente das fábricas e fornecedores, mas também dos consumidores.

\section{QUALIDADE EM SERVIC̣OS NA INTERNET}

Para avaliar a qualidade na prestação de serviços, utilizam-se, como referenciais, os trabalhos dos autores Valerie A . Zeithmal, A. Parasuraman e Leonard L. Berry (1985, 1988 e 1991). Nos seus estudos sobre como os clientes e fornecedores do serviço reavaliam a qualidade em serviços, estes autores desenvolveram um Modelo Conceitual da Qualidade dos Serviços e um instrumento de avaliação denominado SERVQUAL.

Neste contexto, os clientes são representados pelos usuários de Internet que estariam utilizando os serviços de federação de identidade, enquanto que os fornecedores do serviço são as empresas que, na formação de um "Arranjo de Confiança”, estariam oferecendo esses serviços.

O SERVQUAL é um instrumento de escala múltiplo, com alto nível de confiabilidade e validez, baseado na definição 
conceitual da qualidade do serviço e em cinco dimensões que se encontram na pesquisa feita, auxiliando as empresas a compreender melhor as expectativas e percepções dos clientes sobre a qualidade do serviço.

$\mathrm{Na}$ aplicação do SERVQUAL, são respondidas 22 questões tabuladas de 1 a 7 , separadas em dois questionários distintos, utilizados na avaliação das expectativas gerais dos usuários e nas percepções dos fornecedores dos serviços. O resultado é utilizado para identificar hiatos na performance da empresa com relação às cinco dimensões abaixo:

\section{- Elementos tangíveis (questões 1 a}

4): aparência física das instalações, equipamentos, pessoal e materiais de comunicação;

- Confiabilidade (questões 5 a 9): a capacidade de prestar o serviço prometido de modo confiável e dentro do prazo; e habilidade para realizá-lo de forma precisa e consistente;

- Capacidade de resposta (questões 10 a 13): disposição e vontade para ajudar os clientes e proporcionar o serviço prontamente;

- Segurança (questões 14 a 17): o conhecimento e a cortesia de empregados, e a sua habilidade em transmitir confiança e confiabilidade;

- Empatia (questões 18 a 22): a atenção individualizada proporcionada aos clientes;

Parasuraman et al. (1985, p.41-50) identificaram alguns fatores que influenciam a formação das expectativas e das zonas de tolerância dos clientes, tais como os exemplos listados a seguir:

- o que os clientes escutam de outros clientes, isto é, a comunicação boca-a-boca proveniente de amigos, vizinhos e conhecidos, colegas de trabalho;

- as necessidades pessoais de cada cliente, considerando-se suas características físicas, psicológicas e sociais;

- situações de emergência pessoais ou mesmo problemas com o serviço inicial;

- o número de alternativas de que o cliente dispõe;

- a experiência passada na utilização de um serviço, isto é, exposição anterior do cliente ao serviço;

- a comunicação externa do prestador do serviço, isto é, promessas explícitas ou implícitas do serviço. Neste fator também se inclui o papel do preço na formação da expectativa do cliente, além da sua influência no momento de escolha do consumidor.

Uma das conclusões mais importantes desta pesquisa foi a existência de um conjunto de discrepâncias ou hiatos, entre as percepções de qualidade de serviço do executivo e as tarefas associadas ao fornecimento do serviço aos clientes.

Estes hiatos foram distribuídos em quatro classes de discrepâncias que se relacionam com as percepções que os executivos têm sobre a qualidade dos serviços e as funções associadas com a sua prestação aos clientes. Além disso, este modelo vincula as discrepâncias que os clientes percebem na qualidade dos serviços - hiato 5 - com as discrepâncias internas existentes nas empresas fornecedoras de serviços - hiato 1 a 4 .

\section{A s atividades em estudo (federação de de obtenção de vantagem competitiva pela influência positiva na estrutura das indústrias.}

Neste estudo, devido ao caráter exploratório sobre a adoção das atividades de federação de identidade, bem como ao cenário de startup desta tecnologia, da qual não há caso implementado no Brasil, a avaliação é realizada sobre os pontos relacionados ao hiato 1: discrepância entre as expectativas dos consumidores e as percepções da administração quanto a estas expectativas.

Desta forma, em conformidade com o Modelo Conceitual apresentado, para cada lado - cliente e fornecedor - estão sendo aplicadas as seguintes considerações:

- Fornecedor (Amostra 1) - formado por empresas que tenham atividades (transações) no ambiente da Internet e que tenham potencial para implementar as atividades de federação de identidade.

- Cliente (Amostra 2) - formado por usuários em potencial, onde as expectativas e o atendimento de necessidades (satisfação) estão sendo avaliados sobre o potencial de melhoria dos serviços prestados.

Com a crescente popularidade das atividades e serviços no ambiente da Internet, como por exemplo o comércio eletrônico, a avaliação de percepções e expectativas destes clientes se torna muito importante, principalmente quando os vários modelos de medição de satisfação dos usuários amplamente providos e testados por pesquisadores são, na sua maioria, baseados em canais tradicionais de negócio e, portanto, podem não estar apropriados para a avaliação de serviços prestados no ambiente da Internet.

Considerando um web site como parte da conexão entre uma companhia e seus clientes, Iwaarden e Wiele (2002) afirmam que esta conexão reflete os esforços em qualidade que estão presentes através da companhia. Também revelam 
a importância em se prover web sites de alta qualidade para seus clientes: não há contato humano através dos web sites - a interação ocorre através de tecnologia.

Mesmo que companhias possam tentar emular interação humana de forma tecnológica, ainda assim, alguns aspectos da interação humana não podem ser substituídos pela tecnologia, como cortesia, amizade, prontidão, atenção, comprometimento, flexibilidade e clareza (COX; DALE, 2001).

Segundo Iwaarden e Wiele (2002), a ausência destes aspectos deve ser compensada por melhor performance de outros fatores ou por excelentes performances de "novos" fatores específicos do ambiente web.

Considerando cada uma das cinco dimensões no instrumento SERVQUAL - Elementos Tangíveis, Confiabilidade, Capacidade de Resposta, Segurança e Empatia - este trabalho identifica os aspectos relacionados à avaliação de serviços e produtos no ambiente da Internet, bem como aspectos relacionados às atividades em estudo. A seção "Metodologia de Pesquisa" destaca as adaptações desenvolvidas neste trabalho sobre o instrumento SERVQUAL original.

\section{MODELO DE ESTABILIDADE DINÂMICA}

O modelo de estabilidade dinâmica (PINE, 1994) foi concebido como ferramenta para o entendimento do cenário competitivo, influenciado pela globalização, não mais suportado pelas formas tradicionais de administração dos negócios e da produção em massa. Apesar da existência de vários modelos para análise de competitividade e apoio às empresas, o modelo de estabilidade dinâmica se estabeleceu como instrumento de análise e posicionamento estratégico para um ambiente de rápida mudança e de competitividade que não possui nenhuma previsibilidade.

O modelo é construído a partir de uma matriz, cujas dimensões são produto e processo, que por sua vez admitem variações comuns: estabilidade e dinâmica. O cruzamento das dimensões com as variações resulta em quatro categorias de organização produtiva: Produção em Massa, Inovação, Melhoria Contínua e Customização em Massa. Cada categoria possui características próprias de estratégia, organização, automação, informação e de atendimento ao mercado. Embora as categorias não sejam precisas e suas fronteiras não sejam de fácil identificação no campo prático, têm se mostrado de grande utilidade como referência na tomada de decisões.

Este modelo propõe o cruzamento destas quatro categorias, classificando as empresas nos quadrantes:

- Produção em Massa - empresas que possuem processos e produtos estáveis. A vantagem competitiva e a lucratividade neste quadrante estão baseadas na redução de custos, alcançada pela eficiência máxima do capital investido e dos recursos humanos treinados utilizados para atingir produções padronizadas.

- Inovação - empresas que possuem processos e produtos dinâmicos. Neste quadrante, verifica-se a necessidade de constantes inovações nos processos, além de se contar com recursos humanos altamente especializados, com capacidade de exploração de novas idéias, alta habilidade e pouco compromisso com custos de produção.

- Melhoria Contínua - empresas que possuem processos dinâmicos e produtos estáveis. Neste quadrante, ocorrem pequenas transformações melhorando continuamente a performance operacional da produção, bem como a gestão dos processos. Esta melhoria deve seguir de forma rápida e com baixo custo, com especialistas trabalhando em regime permanente de colaboração.

- Customização em Massa - empresas que possuem processos estáveis e produtos dinâmicos. Neste quadrante, verifica-se a capacidade de atender uma grande massa de consumidores com uma variedade de produtos e inovações, em que a rapidez e variedade da produção são aliadas ao baixo custo.

Apesar do propósito focal do modelo na análise da turbulência do mercado, este estudo se utiliza da visão fornecida pelo modelo com o objetivo de observar a capacidade que as atividades de federação de identidade oferecem para as empresas potencializarem as estratégias relacionadas a cada quadrante do Modelo.

\section{METODOLOGIA DE PESQUISA}

Com a funcionalidade de medição de variáveis individuais e grupais, o questionário é o principal instrumento de coleta de dados utilizado nesta pesquisa. Houve a necessidade de adaptar questionários já existentes, bem como de elaborar novos questionários. Para tanto, seguiu-se uma metodologia destacada por Richardson (1999). Os questionários também foram desenvolvidos e aplicados em versão web com base nos princípios ressaltados por Dillman (1998). Desta forma, procura-se obter os benefícios destacados por Gunn (2002), como custo, agilidade e eficiência.

Esta versão em página web é visualizada através de browser acessando a rede Internet nos endereços:

- Instrumento de Medida 1 (Amostra 1):

http://www.jmvinfo.com.br/questestrategia/

- Instrumento de Medida 2 (Amostra 2):

http://www.jmvinfo.com.br/questexp/

Para avaliar o potencial para melhoria dos serviços no ambiente da Internet, adaptou-se o instrumento já testado SERVQUAL para corresponder a serviços específicos das atividades de federação de identidade (QUINTELLA; VILELA, 2004). 
Nas questões referentes à avaliação do aspecto competitivo, busca-se, pela percepção dos executivos, quais atividades da Cadeia de Valor podem ser influenciadas pelas atividades de federação de identidade, bem como a possível influência na estrutura das indústrias, considerando as cinco forças da competitividade (Porter, 1989, 2001): Ameaças de Novos Entrantes, Poder dos Compradores, Poder dos Fornecedores, Produtos Substitutos e Rivalidade dos Concorrentes.

As questões referentes à contribuição das atividades de federação de identidade no posicionamento estratégico das empresas nos quadrantes da matriz Produto-Processo foram desenvolvidas a partir do modelo em que Boyton, Victor e Pine (1993) apresentam as características de "Estratégia" e de "Alinhamento Estratégico de TI" correspondentes a cada quadrante.

Para a amostra utilizada na pesquisa de campo, foram considerados os seguintes aspectos:

- executivos responsáveis pela avaliação de emprego de novas tecnologias vinculadas à Internet pelas empresas que representam.
- empresas que tenham atividades (transações) no ambiente da Internet e que tenham potencial para implementar as atividades de federação de identidade.

- grupo heterogêneo de usuários de Internet.

Com relação à área de atuação do executivo entrevistado dentro da própria empresa, o Quadro 1 apresenta um agrupamento das respostas, conforme classificação adotada no questionário.

Com relação ao cargo ou função exercida pelo executivo entrevistado dentro da própria empresa, o Quadro 2 apresenta um agrupamento das respostas com base em texto obtido pela pergunta do tipo aberta adotada no questionário.

Verifica-se a maior concentração nas áreas de "TI e Sistemas de Suporte" e "Gestão e planejamento estratégico". As duas áreas somadas correspondem a $76 \%$ da amostra. Também se verificou que dos 16 executivos destas duas áreas, 11 assumem a função de Sócio, Diretor ou Gerente. Com isto, a importância estratégica destas duas áreas para

Quadro 1: Área de Atuação dos Entrevistados da Amostra 1.

\begin{tabular}{|l|c|}
\hline \multicolumn{1}{|c|}{ ÁREA DE ATUAÇÃO NA EMPRESA } & RESPONDENTES \\
\hline Engenharia e planejamento de redes & 1 \\
\hline Gestão e planejamento estratégico & 6 \\
\hline Internet & 1 \\
\hline Marketing & 1 \\
\hline Qualidade de Processos, Produtos e TI & 1 \\
\hline Tl e Sistemas de Suporte & 10 \\
\hline Vendas & 1 \\
\hline
\end{tabular}

Fonte: Elaboração própria

Quadro 2: Cargo dos Entrevistados da Amostra 1.

\begin{tabular}{|l|c|}
\hline \multicolumn{1}{|c|}{ GARGO OU FUNÇÃO NA EMPRESA } & RESPONDENTES \\
\hline Sócio & 1 \\
\hline Diretor & 5 \\
\hline Gerente & 6 \\
\hline Coordenador & 1 \\
\hline Supervisor & 1 \\
\hline Consultor & 2 \\
\hline Analista & 4 \\
\hline não informado & 1 \\
\hline
\end{tabular}

Fonte: Elaboração própria 
avaliação de uma nova tecnologia associada à relação de cargos exercidos pelos executivos nas suas empresas validam as respostas obtidas para serem utilizadas para avaliar o potencial de uma tecnologia de trazer vantagens estratégicas para suas empresas.

A fim de se identificar padrões de comportamento sobre as respostas dos executivos da Amostra 1, realizou-se o agrupamento em duas dimensões: segmento de atuação das organizações; e tamanho das empresas em número de funcionários.

A Figura 1 apresenta a distribuição dos entrevistados por segmentos de atuação e por número de empregados da empresa. Neste caso, como a amostra segmentada apresentaria uma granularidade muito alta, decidiu-se por correlacionar as duas faixas de número de empregados: "menos de 500" e "mais de 500”. Desta forma, na análise das questões-chave sobre a Amostra 1, é possível fazer uma correlação entre o segmento de atuação e o tamanho da empresa.
Para a Amostra 2, o Quadro 3 apresenta os dados estatísticos obtidos pelas 22 respostas recebidas:

\section{RESULTADOS}

O estudo sobre o potencial das atividades de federação de identidade de trazer vantagem competitiva foi aplicado a executivos de empresas que exercem atividades no ambiente da Internet e possuem potencial para implementá-las na própria ou em clientes dos seus serviços de tecnologia. A amostra obtida de 21 executivos foi agrupada em vários segmentos de atuação: Telecomunicações, Serviços Financeiros, Tecnologia, Transportes e Outras Atividades.

Considerando uma escala de 0 a 10 e um intervalo t-Student de confiança em 95\%, a Figura 2 apresenta as percepções encontradas com respeito à contribuição das atividades de federação de identidade às metas estratégicas das organizações (PORTER, 1989), em que se destacam

Figura 1: Distribuição das Empresas da Amostra 1 por Segmento e Número de Empregados.

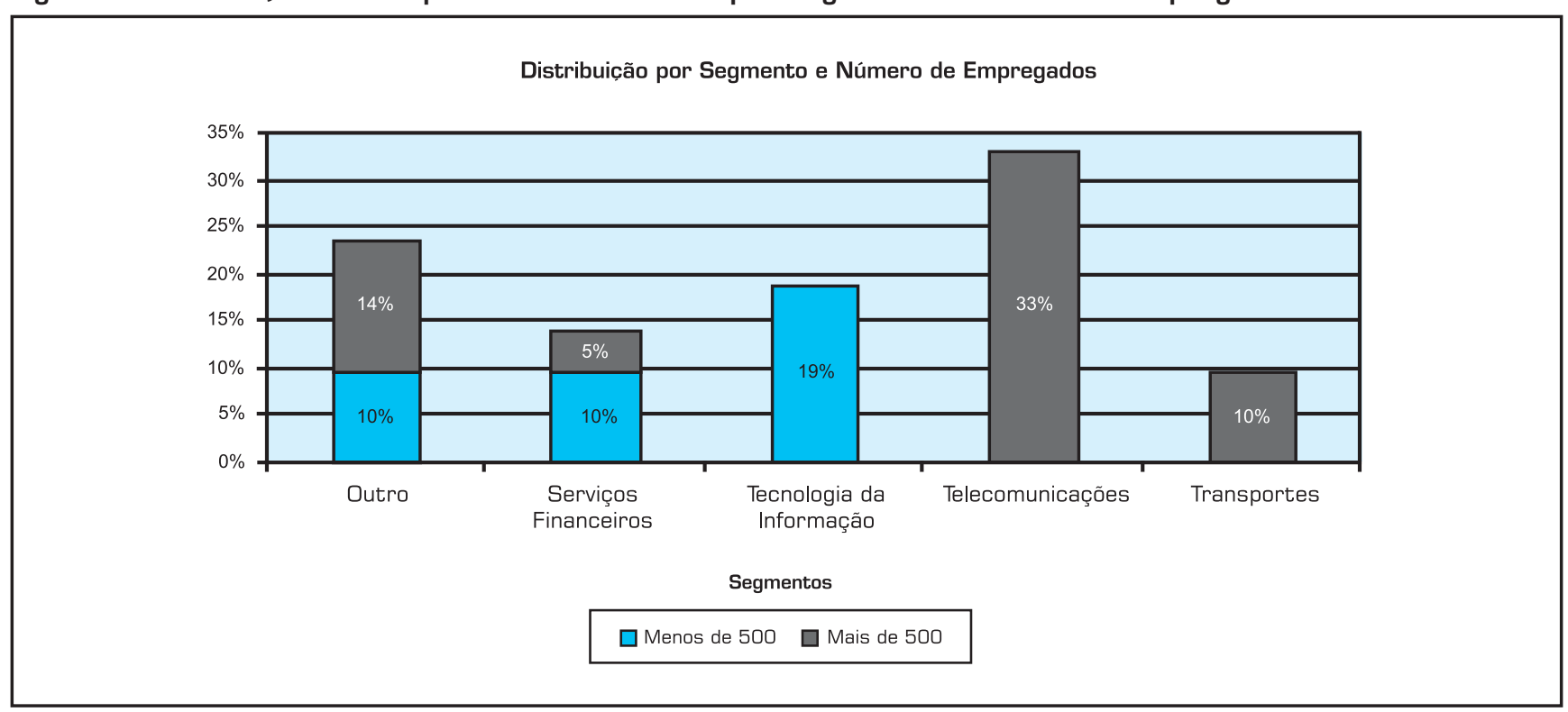

Fonte: Elaboração própria.

Quadro 3: Dados Estatísticos da Amostra 2.

\begin{tabular}{|l|c|c|}
\hline & HOMENS & MULHERES \\
\hline Média de Idade & 31,8 & 29,9 \\
\hline Média de Anos de Experiência na Internet & 7,8 & 6,6 \\
\hline Total & 14 & 8 \\
\hline
\end{tabular}

Fonte: Elaboração própria. 
três das sete metas que obtiveram graus superiores a 5,00: Diferenciação, Complemento e Novos Negócios.

Conforme Figura 3, das nove atividades da Cadeia de Valor (Porter, 2001), destacam-se os graus atribuídos acima de 5,00, em escala de 0 a 10 e um intervalo t-Student de confiança em 95\%, nas atividades primárias Marketing \& Vendas $(6,95 \in[5,42 ; 7,25])$; Serviços $(6,71 \in[5,81 ; 7,61])$; e nas atividades de suporte Infra-estrutura das empresas $(6,33 \in[5,42 ; 7,25])$ e Desenvolvimento de Tecnologia $(7,05 \in[6,24 ; 7,86])$.
Conforme as características de Estratégia e Alinhamento Estratégico de TI, os executivos indicaram a contribuição das atividades conforme a distribuição apresentada na Figura 4.

Para avaliação das expectativas sobre o potencial das atividades em estudo, o levantamento foi conduzido sobre um grupo heterogêneo de 22 usuários, em que o principal requisito é a familiarização com os serviços prestados no ambiente da Internet. Ou seja, é necessário que o usuário já tenha utilizado algum serviço (compras on-line, serviços de

Figura 2: Contribuição ao Modelo de Porter.

\section{Metas Estratégicas}

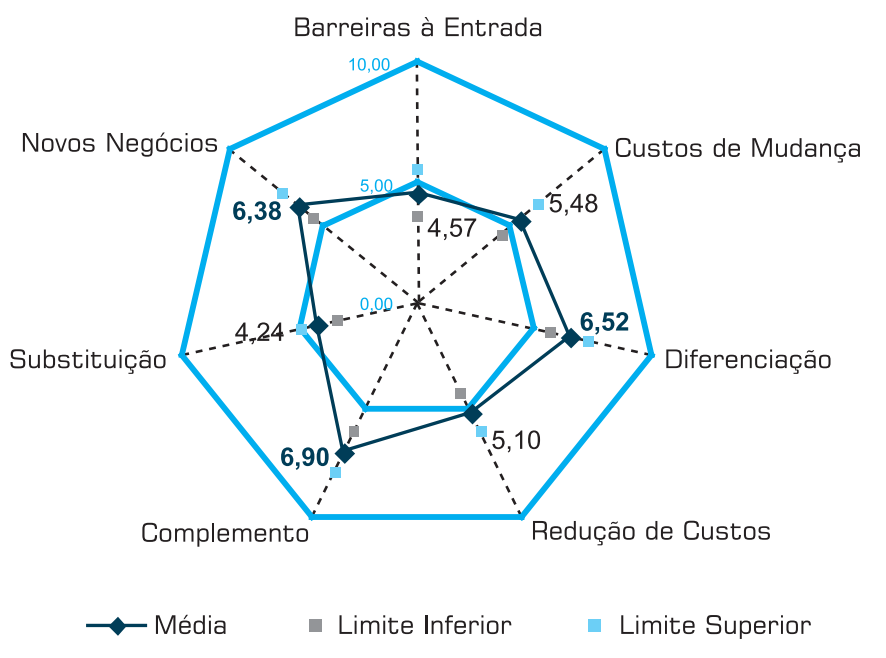

Fonte: Elaboração própria.

Figura 3: Influência das Atividades na Cadeia de Valor.

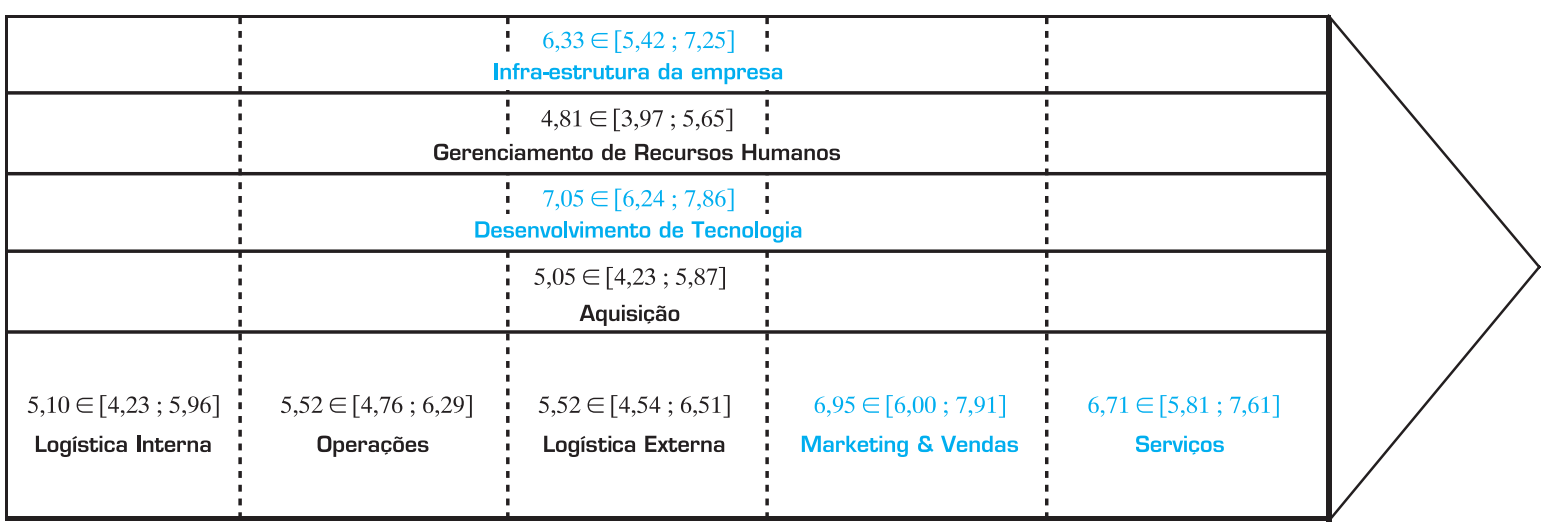

Fonte: Elaboração própria. 
informação etc.) que the tenha exigido um cadastramento para fins de identificação (login e senha). As percepções dos executivos sobre estas expectativas são obtidas sobre a mesma amostra em que as questões sobre competitividade estão sendo aplicadas. uma das cinco dimensões do Modelo Conceitual da Qualidade dos Serviços.

O teste t-Student foi aplicado sobre a diferença entre duas médias, onde o t calculado (tc) é comparado com o t obtido na tabela de distribuição Student, com um coefi-

\section{A $s$ atividades em estudo (federação de identidade) foram percebidas com potencial de obtenção de vantagem competitiva pela influência positiva na estrutura das indústrias.} ciente de confiança em $95 \%$. Através desta análise, verifica-se que a diferença entre a qualidade esperada pelo usuário e a percepção dos executivos sobre esta expectativa é destacada nas dimensões Elementos Tangíveis e Confiabilidade. Também se verificou uma inversão de valores na dimensão Segurança, onde os executivos esperam uma

O Quadro 4 apresenta as diferenças entre as expectativas dos usuários com relação à capacidade das atividades de contribuírem para a melhoria na qualidade dos serviços na Internet e as percepções dos executivos sobre estas expectativas. Estas diferenças foram obtidas agrupando-se as 22 respostas do SERVQUAL das duas atuais amostras em cada avaliação mais positiva dos usuários.

A importância de cada dimensão de qualidade ao ambiente da Internet foi levantada entre os usuários entrevistados, conforme Figura 5. Ressaltam-se os maiores valores atribuídos para Confiabilidade (28\%) e Segurança (25\%).

Desta forma, no gráfico de dispersão (Figura 6) relaciona-

Figura 4: Contribuição das atividades de federação de identidade ao Modelo de Pine.
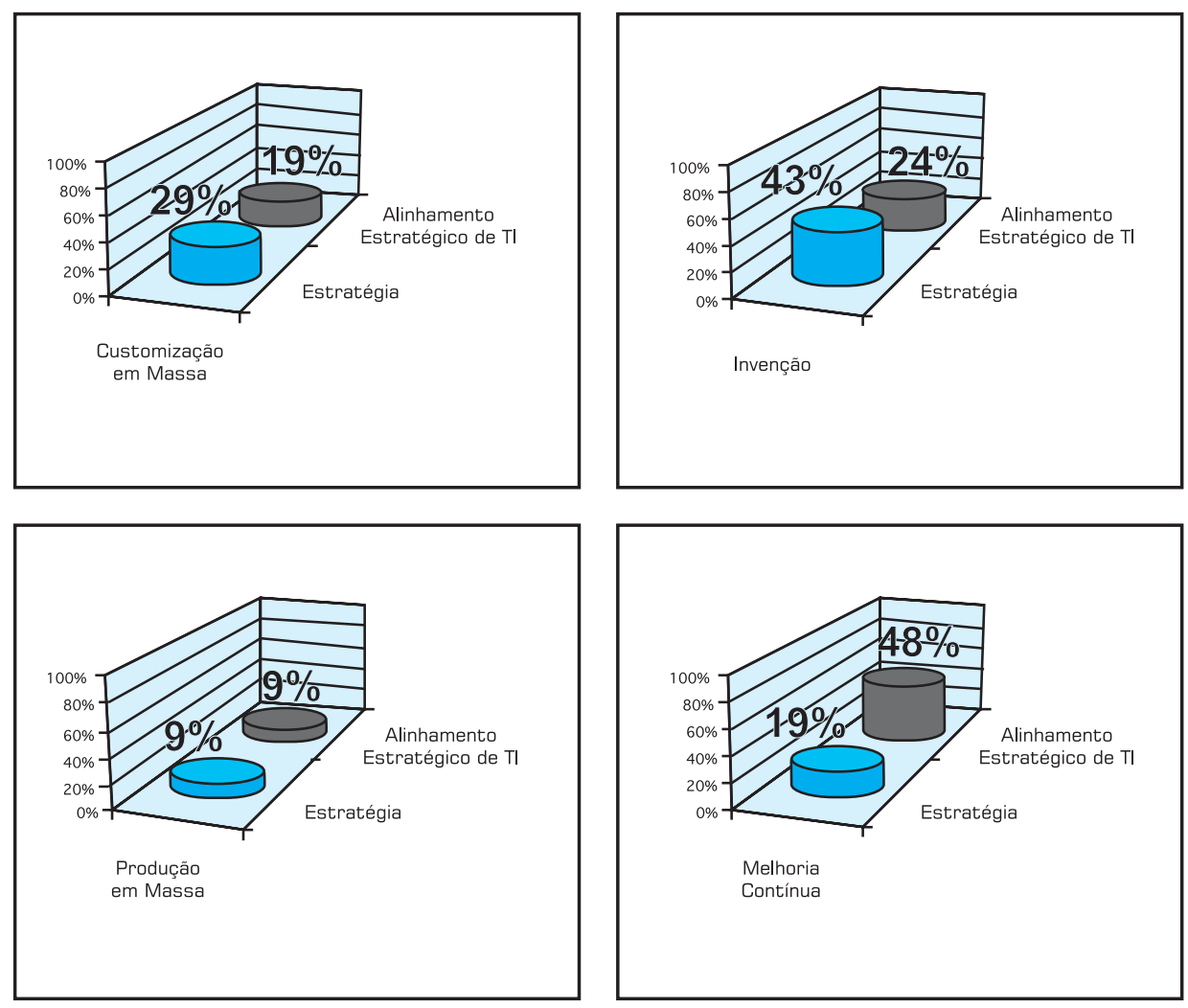

Fonte: Elaboração própria. 
se a importância geral impetrada pelos usuários (Amostra 2) às dimensões de qualidade no ambiente da Internet com os valores obtidos das expectativas médias dos mesmos usuários com relação à capacidade das atividades em estudo contribuírem para as empresas nos quesitos associados às mesmas dimensões de qualidade.

Considerando uma distribuição igual de grau de importância em 20\% para cada dimensão de qualidade, determinou-se este valor de $20 \%$ como corte para se definir a escala dividida em importância alta (maior que 20\%) e importância baixa (menor que 20\%). Para o eixo das expectativas, considerou-se a escala de Likert de 1 a 7 utilizada na coleta de dados, em que o grau 4,00 é o ponto médio de corte para se definir a expectativa alta (maior que 4,00 ) e a expectativa baixa (menor que 4,00).
Com isto, verificou-se que as dimensões Confiabilidade, Segurança e Elementos Tangíveis se posicionaram no quadrante "Importância alta - Expectativa alta" e as dimensões Capacidade de Resposta e Empatia se posicionaram no quadrante "Importância baixa - Expectativa alta". Ou seja, para todas as dimensões os usuários atribuem uma expectativa alta de que as Atividades em estudo irão contribuir para melhoria dos quesitos de qualidade relacionados.

A Figura 7 apresenta os mesmos valores atribuídos para Importância e Expectativa considerando apenas os quadrantes relacionados à expectativa alta. Para uma análise em cima de posições relativas, determinou-se a expectativa média $(5,56)$ como valor de corte para o eixo $X$.

Ressalta-se que mesmo sendo a dimensão com segundo maior grau de importância, a Segurança é a que recebe

Quadro 4: Diferenças agrupadas pelas dimensões de qualidade.

\begin{tabular}{|c|c|c|c|c|c|}
\hline \multirow[t]{2}{*}{ DIMENSÃO } & \multirow[t]{2}{*}{ TC } & \multirow{2}{*}{$\begin{array}{c}\text { P(TG) } \\
\text { BI-GAUDAL }\end{array}$} & USUÁRIOS & EXECUTIVOS & \multirow{2}{*}{$\begin{array}{l}\text { HIATO } \\
\text { (1) E (2) }\end{array}$} \\
\hline & & & $\begin{array}{c}\text { EXPEGTATIVA } \\
\text { (1) }\end{array}$ & $\begin{array}{c}\text { PERCEPGÃO DA } \\
\text { EXPECTATIVA } \\
\text { (2) }\end{array}$ & \\
\hline Elementos Tangíveis & 2,1583 & 0,0368 & 6,034 & 5,452 & 0,582 \\
\hline Confiabilidade & 1,8262 & 0,0751 & 5,482 & 4,924 & 0,558 \\
\hline Capacidade de Resposta & 0,7591 & 0,4521 & 5,443 & 5,214 & 0,229 \\
\hline Segurança & $-0,4083$ & 0,6852 & 5,045 & 5,214 & $(0,169)$ \\
\hline Empatia & 1,5081 & 0,1392 & 5,836 & 5,381 & 0,455 \\
\hline
\end{tabular}

Fonte: Elaboração própria.

Figura 5: Importância das Dimensões na Qualidade.

\section{Importância das Dimensões de Qualidade}

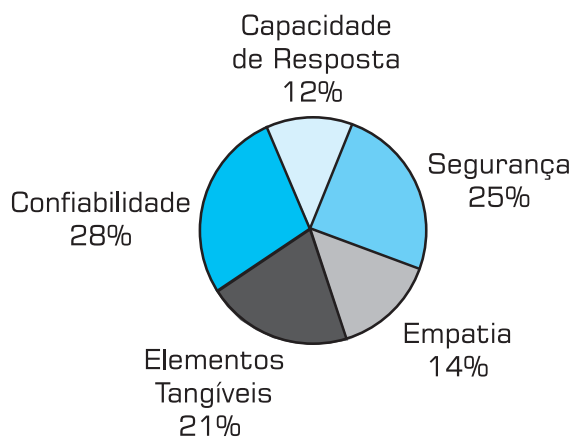

Fonte: Elaboração própria. 
Figura 6: Importância versus Expectativa sobre as Dimensões na Qualidade.

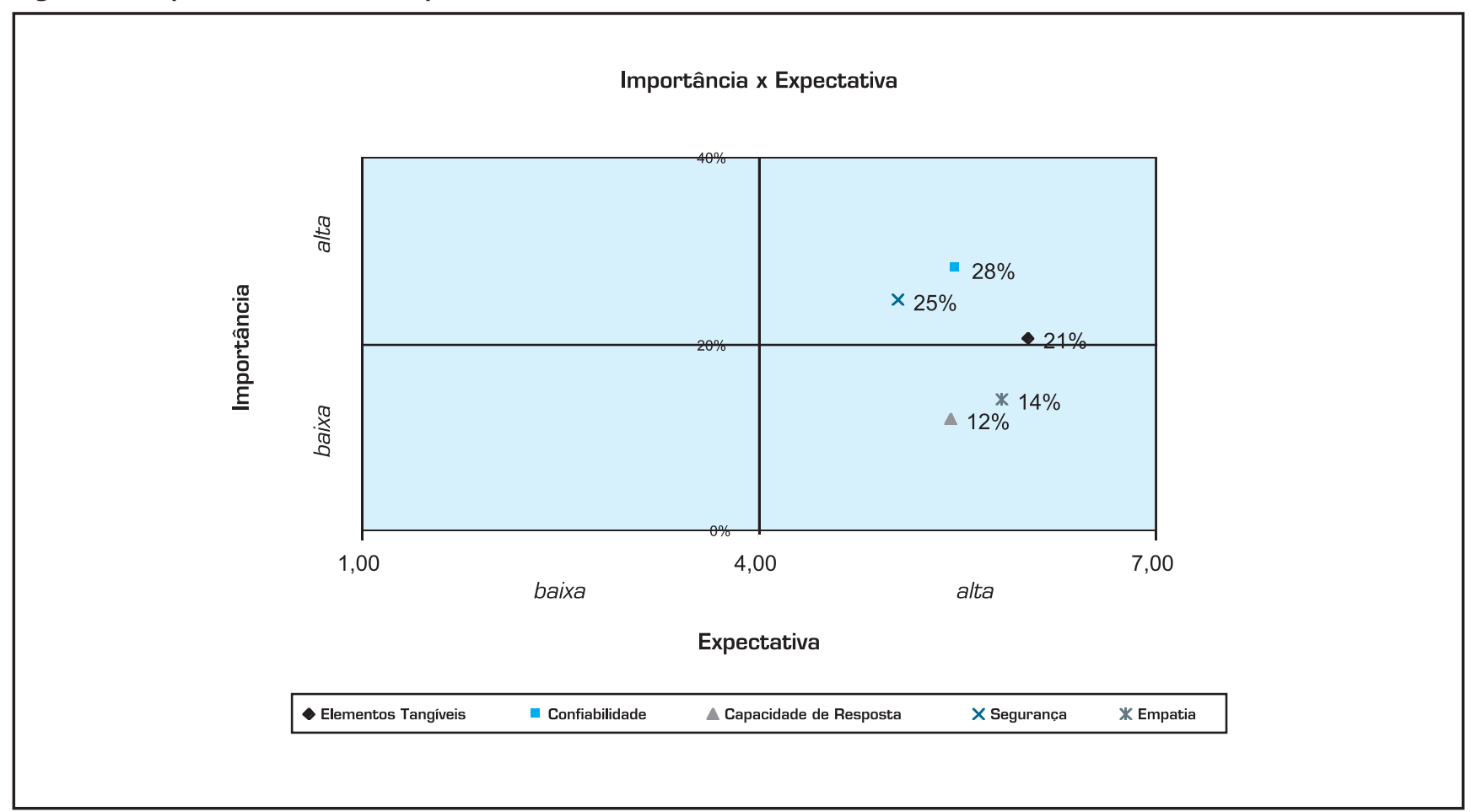

Fonte: Elaboração própria.

Figura 7: Importância versus Expectativa sobre as Dimensões na Qualidade em escala relativa.

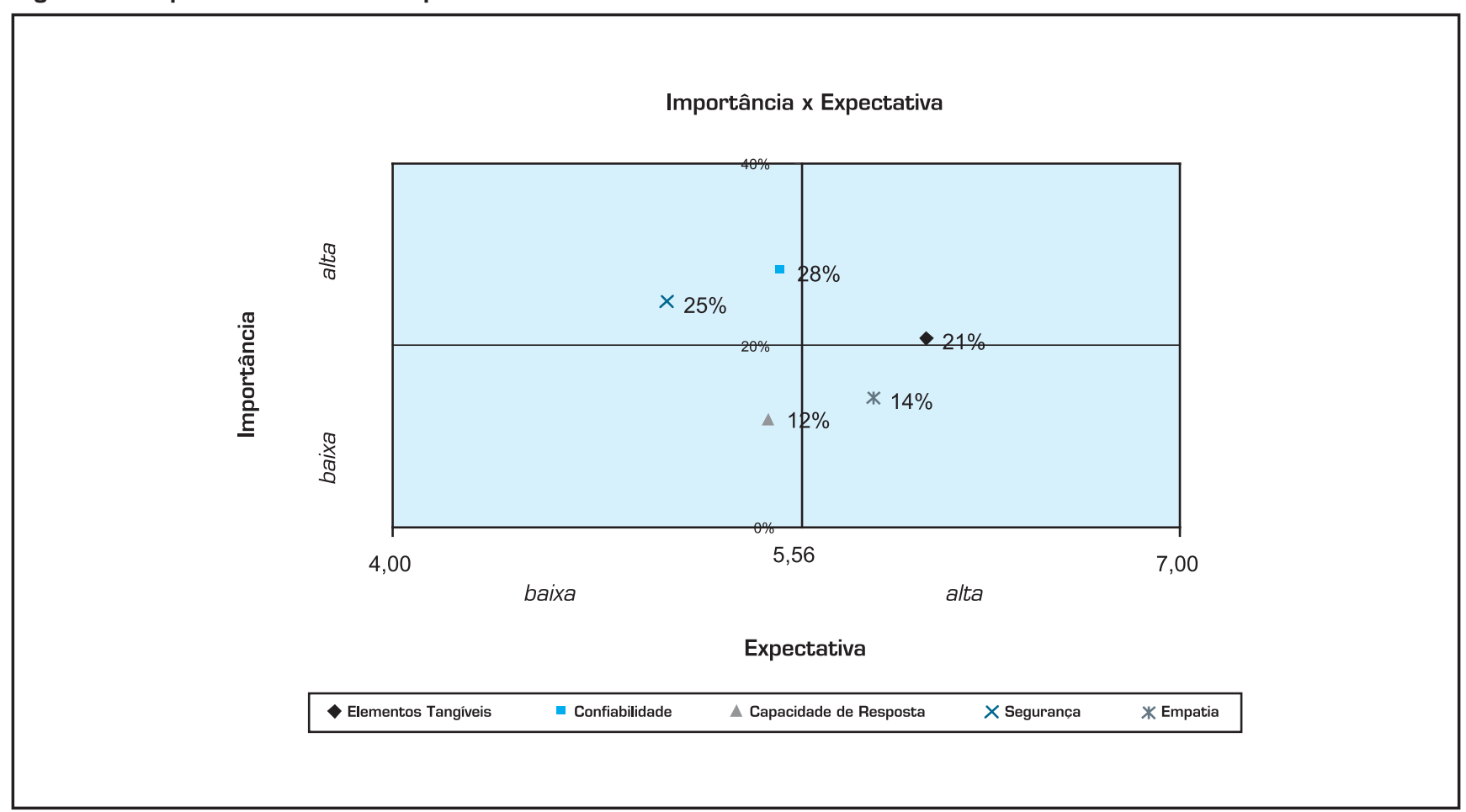

Fonte: Elaboração própria. 
menor média nas expectativas dos usuários. Outro foco de análise importante é a dimensão da Confiabilidade, que recebeu o maior grau de importância, porém, com uma expectativa $(5,48)$ abaixo da média geral das dimensões analisadas $(5,56)$.

\section{CONCLUSÕES}

As atividades de federação de identidade foram percebidas com potencial de obtenção de vantagem competitiva pela influência positiva na estrutura das indústrias, pois, das sete metas estratégicas tomadas como premissas de obtenção de vantagem competitiva, é plausível afirmar que as metas estratégicas "Diferenciação", "Complemento" e "Novos Negócios" são favorecidas pelas atividades em estudo por receberem graus acima de 5 em uma escala de 0 a $10 \mathrm{com}$ índice de confiança em $95 \%$.

Sugere-se que a meta estratégica "Substituição" não foi tão positivamente avaliada pelo receio de serviços ou produtos concorrentes provenientes da proliferação de novas tecnologias neste ambiente, assim como a meta estratégica "Barreiras à Entrada" não foi tão positivamente avaliada pelo grau de incerteza e dinamismo nos negócios do ambiente da Internet - reforçando a afirmação de Porter (2001) de que aplicações de Internet são difíceis de se manterem proprietárias contra novos entrantes.

Como a abordagem desta pesquisa toma como foco os serviços que podem ser prestados pelas empresas através da tecnologia ou práticas tecnológicas das atividades em estudo, reforça-se a idéia de que os negócios que podem ser criados ou melhorados com estas atividades não permitem "aprisionar" a tecnologia em si, e portanto, teme-se que as tecnologias relacionadas possam ser utilizadas também por concorrentes em um momento posterior. Esta proposição não invalida a capacidade potencial de as atividades de federação trazerem vantagem competitiva, porém, é um argumento de rejeição à afirmação de que esta vantagem seja "sustentável".

Algumas conclusões foram também obtidas sobre as análises das percepções sobre as metas estratégicas quando estas foram agrupadas por segmento de atuação das empresas dos entrevistados. Estas conclusões estão destacadas no Quadro 5.

Segundo os executivos, as atividades em estudo contribuem com maior ênfase às características estratégicas como "Desenvolvimento de um produto/serviço ou processo que seja novo ou único no mercado", e de alinhamento estratégico de TI, como "Projeto de sistemas de comunicação e informação cruzada que suportem transformações incre- mentais e constantes", colaborando no posicionamento da organização tanto no quadrante de "Inovação" quanto de "Melhoria Contínua" do Modelo de Pine. Considerando a matriz produto-processo, este resultado reflete o que tecnologias de Internet podem oferecer quando se considera uma ambiente de processos dinâmicos nas organizações.

Sugere-se que a maior diferença obtida entre as percepções e expectativas em relação à dimensão de qualidade Elementos Tangíveis (facilidade de manuseio, apresentação, armazenamento e atualização das informações de identidade) pode ser oriunda de uma atual postura mais cautelosa dos executivos com relação à satisfação do usuário no ambiente da Internet. Ou seja, esta postura cautelosa é a confirmação de que a tendência atual, à qual os executivos estão sujeitos, é de se exigir maior fundamento e mais justificativas para, daí, se considerar válida uma onda convergente de tecnologia (AberdeenGroup, 2002). tividades de Federação de Identidade
trazem vantagem competitiva, porém,
pela capacidade de replicação da tecnologia, esta vantagem pode não ser 'sustentável'.

A dimensão Segurança obteve não somente a menor média atribuída, como o menor hiato entre as expectativas e a percepção das expectativas, revelando uma preocupação real e comum a usuários e a executivos de se exigir esta qualidade específica a uma tecnologia que envolve o uso de informações particulares com alto nível de confidencialidade.

Na dimensão Segurança, o maior grau obtido no item relacionado à capacidade de transmitir confiança através de empresas certificadoras das ações e transações sugere que esta dimensão de qualidade sobre as atividades em estudo pode ser beneficiada pelo emprego de tecnologias adicionais como certificação digital, que já tem implementação e presença no ambiente da Internet.

Ainda na dimensão Segurança, o menor grau obtido no item relacionado à capacidade de se impedir que haja propagação de informações de forma indevida pode evidenciar os questionamentos gerais sobre a crescente onda de propagação de informações indevidas, como e-mails com vírus, spam, boatos etc. Neste aspecto, esta dimensão pode estar sendo afetada diretamente pelos efeitos que esta prática abusiva no ambiente da Internet gera dia-a-dia. E desta forma, tanto as empresas desenvolvedoras das tecnologias embutidas nas atividades de federação de identidade quanto as empresas que venham a implementar estas atividades 
nas suas unidades de negócio na Internet devem, como sugestão, estar cientes de uma possível correlação entre a expectativa sobre esta qualidade e a incidência geral das práticas abusivas na Internet.

No levantamento sobre a importância de cada dimensão, os maiores valores foram obtidos nas dimensões Confiança e Segurança - o que reforça a importância dada a uma tecnologia que envolve o uso de informações particulares com alto nível de confidencialidade.

Considerando as análises sobre a importância versus expectativas atribuídas pelos usuários para cada dimensão de qualidade, verificou-se que todas as dimensões receberam alta expectativa (maior que o grau 4,00, que, o valor médio da escala adotada). Porém, na relação com a importância atribuída pelos mesmos usuários, destaca-se a alta importância atribuída para as dimensões Confiabilidade, Segurança e Elementos Tangíveis. Sugere-se que este quadrante "Importância alta - Expectativa alta" exige uma atenção maior por parte dos executivos ao implantarem e promoverem as atividades de federação de identidade nos

Quadro 5: Conclusões sobre atendimento às Metas Estratégicas por Segmento.

\begin{tabular}{|c|c|c|}
\hline $\begin{array}{c}\text { META } \\
\text { ESTRATÉEIGA }\end{array}$ & $\begin{array}{l}\text { SEGMENTO QUE } \\
\text { ATRIBUIU MAIOR GRAU }\end{array}$ & $\begin{array}{l}\text { CONGLUSÕES } \\
\text { SUGERIDAS }\end{array}$ \\
\hline $\begin{array}{l}\text { Barreiras à Entrada e } \\
\text { Custos de Mudança }\end{array}$ & Transportes & $\begin{array}{l}\text { Como este segmento utiliza a tecnologia de Internet } \\
\text { para prestar serviços para outras empresas, a } \\
\text { utilização apropriada de tecnologias em Extranet } \\
\text { (utilizada como canal de serviços para outras empresas) } \\
\text { pode aumentar a sua base clientes, bem como, de criar } \\
\text { barreiras para novos concorrentes. } \\
\text { Pelo fato deste segmento não ter foco nesta tecnologia, } \\
\text { espera-se que não haja, por parte da concorrência, um } \\
\text { dinamismo tão grande na seleção e emprego de novos } \\
\text { serviços tecnológicos e, desta forma, a vantagem } \\
\text { competitiva se torna mais sustentável. }\end{array}$ \\
\hline Redução de Custos & Serviços Financeiros & $\begin{array}{l}\text { As instituições financeiras são importantes } \\
\text { implementadoras da tecnologia na redução de custos das } \\
\text { suas operações. } \\
\text { Desta forma, esta situação está não somente coerente } \\
\text { com a realidade deste segmento de atuação do mercado, } \\
\text { como confirma a importância estratégica das Atividades } \\
\text { em estudo ao alcançar o âmago da necessidade de um } \\
\text { setor. }\end{array}$ \\
\hline Complemento & Telecomunicações & $\begin{array}{l}\text { O interesse que o segmento de Telecomunicações possui } \\
\text { sobre as Atividades em estudo para consecução desta } \\
\text { meta estratégica pode estar relacionado ao cenário de } \\
\text { expansão deste setor no Brasil, que nos últimos anos } \\
\text { (após abertura e privatização neste mercado] levou ao } \\
\text { surgimento de diversas novas empresas e serviços, } \\
\text { com criação de novas parcerias para oferecer serviços } \\
\text { adicionais e complementares. } \\
\text { Ou seja, para este segmento, as Atividades em estudo } \\
\text { trazem vantagem competitiva ao permitir, através } \\
\text { desta meta estratégica, de forma contínua, serviços } \\
\text { agregados que tragam a fidelização de sua base de } \\
\text { clientes. }\end{array}$ \\
\hline
\end{tabular}

Fonte: Elaboração própria. 
seus negócios. Ou seja, neste caso, se a percepção sobre os serviços prestados não atender às expectativas observadas, a conseqüência pode ser mais negativa tendo em vista que os mesmos usuários atribuíram alta importância para estas dimensões de qualidade.

$\mathrm{Na}$ análise da distribuição relativa das dimensões nos eixos importância e expectativa, destacam-se as dimensões Confiabilidade e Segurança, que possuem os maiores graus de importância e estão abaixo da média geral das expectativas $(5,56)$. Ou seja, nesta visão, estas dimensões apresentam-se como uma oportunidade para que as empresas, ao promoverem e implantarem as atividades em estudo com a atenção aos quesitos de qualidade relacionados a estas dimensões, consigam trazer uma percepção de melhoria nos serviços prestados (QUINTELLA; VILELA, 2006).

A partir das análises obtidas neste trabalho, o Quadro 6 apresenta sinteticamente respostas aos questionamentos de Porter (2001) quanto ao canal da Internet, agora aplicados à potencialidade das atividades de federação de identidade.

Quadro 6: Questionamentos de Porter aplicados às atividades de federação de identidade.

\begin{tabular}{|l|l|}
\hline $\begin{array}{l}\text { Quem irá capturar os benefícios que a } \\
\text { Internet cria? }\end{array}$ & $\begin{array}{l}\text { Atividades de Federação de Identidade e facilitam a experiência dos usuários através } \\
\text { de single sign-on e oferta de serviços relacionados ou } \\
\text { complementares. }\end{array}$ \\
\hline $\begin{array}{l}\text { Qual será o impacto da Internet sobre a } \\
\text { estrutura das indústrias? }\end{array}$ & $\begin{array}{l}\text { Fortalecem as metas estratégicas "Diferenciação", } \\
\text { "Complemento" e "Novos Negócios". }\end{array}$ \\
\hline $\begin{array}{l}\text { A Internet será capaz de aumentar ou } \\
\text { reduzir as receitas? }\end{array}$ & $\begin{array}{l}\text { Permitem aumentar as receitas através de novos } \\
\text { negócios ou parcerias para complementar a oferta de } \\
\text { produtos ou serviços. }\end{array}$ \\
\hline $\begin{array}{l}\text { Qual será o impacto na estratégia das } \\
\text { empresas? }\end{array}$ & $\begin{array}{l}\text { Permitem o desenvolvimento de um produto/serviço } \\
\text { ou processo que seja novo ou único no mercado e dão } \\
\text { subsídios para projeto de sistemas de comunicação } \\
\text { e informação cruzada que suportem transformações } \\
\text { incrementais e constantes. }\end{array}$ \\
\hline $\begin{array}{l}\text { A Internet ajuda ou prejudica a capacidade } \\
\text { das companhias obterem vantagem } \\
\text { sustentada sobre os seus competidores? }\end{array}$ & $\begin{array}{l}\text { Trazem vantagem competitiva, porém, pela capacidade } \\
\text { de replicação da tecnologia, esta vantagem pode não ser } \\
\text { "sustentável". }\end{array}$ \\
\hline
\end{tabular}

Fonte: Elaboração própria.

\author{
Artigo recebido em 21/12/2005 \\ Aprovado para publicação em 10/05/2007
}




\section{- Referências}

ABERDEENGROUP. (2002). Federated Identity Systems: An Executive White Paper. Internet: http://www.aberdeen. com/2001/research/05022764.asp

BOYNTON, A. C.; VICTOR, B.; PINE, B. J. New Competitive Strategies: Challenges to Organizations and Information Tecnology. IBM System Journal, v. 32, n. 1,1993

COX, J.; DALE, B. G. Service quality and e-commerce: an exploratory analysis. Managing Service Quality. v. 11, n. 2, p. $121-131,2001$

DILLMAN, D. A.; TORTORA, R. D.; BOWKER, D. Principles for Constructing Web Surveys. Pullman, Washington, SESRC Technical Report 98-50, 1998. Internet: http://survey.sesrc.wsu.edu/ dillman/papers/websurveyppr.pdf

GUNN, H. Web-based Surveys: Changing the Survey Process. First Monday PeerReviewed Journal on the Internet, v. 7, n. 12, December 2002. Internet: http:// firstmonday.org/issues/issue7_12/gunn/

IBM; MICROSOFT; VERISIGN. Web Services Security Language. Version: 1.0, April, 2002a. Internet: http://www. verisign.com/wss/wss.pdf
IBM; MICROSOFT; BEA; SAP. Web Services Policy Framework. Version: 1.0 December 2002b. Internet: http://www. verisign.com/wss/WS-Policy.pdf

IBM; MICROSOFT; RSA; VERISIGN. Web Services Trust Language. Version: 1.0 , December 2002c. Internet: http://www. verisign.com/wss/WS-Trust.pdf

IBM; MICROSOFT; BEA; RSA; VERISIGN. Web Services Federation Language. Version: 1.0, July 2003. Internet: http:// www.verisign.com/wss/WS-Federation. pdf

IWARDEEN, . V.; WIELE, T. V. D. A study on the applicability of SERVQUAL dimensions for web sites. Erasmus Research Institute of Management. Rotterdan: Erim Report Series Research in Management, 2002.

LIBERTY ALLIANCE PROJECT. Liberty ID FF Implementation Guidelines. Version: Draft 1.2-08, April, 2003a. Internet: http://www.projectliberty.org/specs/ draft-lib-arch-idff-guidelines-v1.2-08 pdf

LIBERTY ALLIANCE PROJECT. Liberty IDFF Architecture Overview. Version: Draft 1.2-04, July 2003b. Internet: http://www. projectliberty.org/specs/draft-lib-archoverview-v1.2-04.pdf
LIBERTY ALLIANCE PROJECT. Liberty IDFF Bindings and Profiles Specification. Version: Draft 1.2-14, July 2003c. Internet: http://www.projectliberty.org/ specs/draft-lib-arch-bindings-profilesv1.2-14.pdf

OASIS Security Assertion Markup Language (SAML). SAML V1.1 Standard Specification. September 2003. Internet: http://www.oasis-open.org/committees/ download.php/3400/oasis-sstc-saml-1 .1-pdf-xsd.zip

PARASURAMAN, A.; ZEITHAML, V. A.; BERRY, L. L. A conceptual Model of Service Quality and Its Implicans for Future Research. Journal of Marketing, v. 49, p. 41-50, Fall, 1985.

PARASURAMAN, A.; ZEITHAML, V. A.; BERRY, L. L. SERVQUAL: A MultipleItem Scale for Measuring Consumer Perceptions of Service Quality. Journal of Retailing, v. 69, n. 1, p. 12-40, Spring, 1988.

PARASURAMAN, A.; ZEITHAML, V. A.; BERRY, L. L. Understanding Customer Expectations of Service. Sloan Management Review. p. 39-48, 1991.
PORTER, M. E. Vantagem Competitiva: criando e sustentando um desempenho superior - tradução por Elizabeth Maria de Pinho Braga. Rio de Janeiro: Campus, p. 83-106, 1989.

PORTER, M. E. Strategy and the Internet. Harvard Business Review, March 2001.

PINE, B. J. Personalizando Produtos e Serviços. São Paulo: Makron Books, 1994.

QUINTELLA, H. L. M. M.; VILELA, J. M. F. Competitividade e Qualidade Percebida: estudo sobre as atividades de Federação de Identidade. Tendências do Trabalho, Rio de Janeiro, 357, p. 28-34, 2004.

QUINTELLA, H. L. M. M.; VILELA, J. M. F. (2006). Strategic Analysis of Identity Federation with Brazilian Companies and Users. In: Business Association of Latin American Studies - BALAS, Lima, 2006.

RICHARDSON, R. J. Pesquisa social: métodos e técnicas. 3. ed. São Paulo Atlas, 1999.

\section{- Sobre os autores}

\section{Heitor M. Quintella, DSc}

Certified Management Consultant

Universidade Federal Fluminense

Professor associado aposentado UFF

Professor visitante UERJ

End.: Rua Piratininga, 15 ap. 902 - Gávea - CEP 22451-130 - Rio de Janeiro - RJ - BRASIL

Tel.: (21) 9973-7723 (cel.) / (21) 2239-0405 ramal: 5451 (UFF)

Fax: (21) 2629-5451 (UFF)

E-mail: hquintel@unisys.com.br

\section{José Marcelo de Freitas Vilela, M.Sc., PMP}

Accenture

Gerente

End.: Av. República do Chile, 500 18o andar - Centro - CEP 20031-170 - Rio de Janeiro - RJ - BRASIL

Tel.: (21) 9731-7699 / (21) 4501-9013

E-mail: jmarcelo@jmvinfo.com.br 